\title{
FLEXURAL DUCTILITY OF LIGHTWEIGHT-AGGREGATE CONCRETE BEAMS
}

\author{
Luís F. A. BERNARDO, Miguel C. S. NEPOMUCENO, Hugo A. S. PINTO \\ Department of Civil Engineering and Architecture, C-made: Centre of Materials and Building Technologies, \\ University of Beira Interior, 6201-001 Covilhã, Portugal
}

Received 03 Jun 2013; accepted 05 Jul 2013

\begin{abstract}
This paper describes an experimental study on the flexural ductility of lightweight-aggregate concrete beams including concretes with compressive strengths between 22.0 and $60.4 \mathrm{MPa}$ and dry densities between $1651 \mathrm{and} 1953 \mathrm{~kg} / \mathrm{m}^{3}$. Nineteen simply supported beams were tested until failure. Two symmetrical concentrated loads were applied at approximately one third of the span. Ductility was studied by defining ductility indexes. The main variables are the concrete compressive strength and the longitudinal tensile reinforcement ratio. It is shown that the parameter with higher influence on ductility is the longitudinal tensile reinforcement ratio. The test results are also compared with the requirements from some codes of practice. It is shown that ACI Code requirements give more guaranties as far as ductility is concerned, when compared with European codes.
\end{abstract}

Keywords: beams, reinforced concrete, lightweight-aggregate concrete, flexure, ductility, codes of practice.

\section{Introduction}

In the last decades, the chemicals and minerals have evolved, so Lightweight Aggregate Concretes (LWAC) has seen successive improvements. The advantages of using concretes with higher strengths and lighter weights in several applications are recognized. Such applications include offshore and marine structures, slabs and joists in high rise buildings, bridge decks in highway bridge structures, pavement rehabilitation and strengthening of existing buildings and precast elements. In some structural members the density of the concrete is often more important than strength because self-weight can represents a very large proportion of total load.

Despite several published studies, existence of specific regulations and reports of successful applications, the current state of knowledge is still far less consolidated compared with normal density concrete, and there are still aspects that justify further investigation. The lightweight aggregates introduce several peculiarities in the properties of concrete, making the predictability of their behavior more complex. The failure mode depends on the level of strength, characteristics of mortar, type and volume content of lightweight aggregate (Bogas, Gomes 2013). From the point of view of the structural behavior, it demands up special care in design, safety check and detailing of reinforcement, due to its low tensile/compressive strength ratio, low fracture toughness and high brittleness (Domagala 2011; Cui et al. 2012).
The low deformability of concrete, however, does not necessarily result in the low deformability of the structural elements made from such concrete. In fact, several studies shown that it is possible to combine positively the relative fragility of the concrete with the incorporation of reinforcing bars. This was confirmed by a number of studies for beams under flexure built with Normal-Weight Aggregate Concrete (NWAC), including both Normal Strength (NS) and High Strength (HS) concrete beams (for instance, Shin et al. 1989; Shehata I., Shehata L. 1996; Bernardo, Lopes 2003, 2004). This is also true for LWAC beams. However, marked differences may exist between flexural ultimate behavior of LWAC and NWAC beams (Sin et al. 2010). For instance, it was shown that the ductility of HS LWAC beams is lower than HS NWAC beams (Liu et al. 2006; Jung et al. 2007). This is because LWAC is more brittle than NWAC, both in tension and compression.

The standard NP EN 206-1:2007 (2007) considers high-strength lightweight concrete above the strength class LC50/55, while the ACI 213 R (2003) refers to 28 -day compressive strength of $6000 \mathrm{psi}(40 \mathrm{MPa})$ or greater. Then, it is expected that, for LWAC beams, the concern with ductility may arise for lower compressive strength of concrete when compared with NWAC beams.

Some techniques to improve LWAC have been studied, such as the incorporation of fibres (Domagala 2011). Among several improvements, it was shown that steel

Corresponding author: Luís F. A. Bernardo

E-mail: lfb@ubi.pt 
fibres improve the post-peak deformability of LWAC in compression (Domagala 2011) and the toughness of concrete (Balendran et al. 2002). However, LWAC with steel fibres becomes more expensive.

Nowadays, it is recognized that structural members must not only provide adequate strength but should also insure adequate ductility under overload condition. This important property is directly related to the capacity for redistributing internal forces and with structural safety.

Flexural performance of LWAC beams still continues to be studied because several requirements of codes of practice continue to be based on the experimental results of NWAC beams. Recent papers about this subject, including HS LWAC beams, can be found in the literature (for example, Liu et al. 2006; Jung et al. 2007; Sin et al. 2010; Arslan, Cihanli 2010; Ho, Zhou 2011). This shows that several aspects about flexural performance of LWAC beams are not fully clarified.

\section{Research significance}

The inelastic deformability of Reinforced Concrete (RC) flexural members depends on a number of factors, including: the longitudinal tensile and compressive reinforcement ratio, the transversal reinforcement ratio and the concrete compressive strength. Several studies on NWAC beams, including HS concrete, confirmed the influence of the above-mentioned parameters (for example, Shin et al. 1989; Bernardo, Lopes 2003, 2004; Arslan, Cihanli 2010). Some of the studies already checked the behavior of LWAC beams, including HS concrete (for instance, Ahmad, Barker 1991; Ahmad, Batts 1991; Ahmad et al. 1995; Liu et al. 2006; Jung et al. 2007; Sin et al. 2010).

Although the studies about flexure generally agree with one another with respect to the influence of the above parameters on ductility, it is nonetheless still not certain how concrete strength affects ductility. Some authors (for example Ahmad, Barker 1991; Shehata I., Shehata L. 1996) observed a loss of ductility in the beams as the concrete's compressive strength increases. Other studies (for example, Shin et al. 1989; Bernardo, Lopes 2003, 2004) observed the opposite. With respect to the effect of the longitudinal tensile reinforcement ratio, all studies mentioned above agree that ductility decreases as this ratio increases. However, different range of appropriate values for this ratio has been defined by the authors.

Studies on LWAC beams, including HS concrete, are still being reported in recent publications. In consequence, proposals for the extension of current codes of practice to include LWAC, including HS concrete, have been reported. Among these, the recommendations by Faust (2000) and Fib (2000) deserve special attention. However, these recommendations are not fully incorporated into the European codes, and more studies need to be carried out in order to provide design rules that could be widely accepted by designers and researchers.

Moreover, only a limited number of studies specifically focused on the ductility of LWAC beams under flexure still exist in the literature (for instance, Ahmad, Barker 1991; Ahmad, Batts 1991; Liu et al. 2006; Jung et al. 2007). Since flexural ductility is essential for structures, a study especially focused on the ductility of LWAC beams is very important.

\section{Description of the experimental work}

This work involved destructive tests being carried out on nineteen RC beams made from LWAC, including concretes from 22.0 to $60.4 \mathrm{MPa}(150 \mathrm{~mm}$ cube specimens) and dry densities between 1651 to $1953 \mathrm{~kg} / \mathrm{m}^{3}$. The beams (Fig. 1) had a total length of $2.6 \mathrm{~m}$ and an average transverse rectangular section of $15 \mathrm{~cm}(b) \times$ $30 \mathrm{~cm}(h)$. The experimental beams were supported simply near the ends and subjected to a symmetrical load composed of two equal concentrated forces, applied at intervals of approximately one third of the span. The central region of the beams (failure zone), between the applied forces, was under pure bending.

In order to prevent shear failure in the region near the supports, stirrups placed close together were provided outside the central zone. Central zone of the beams does not include transversal reinforcement so that the compressive concrete in the sections would not be confined by the triaxial state conferred by the girdling effect produced by the stirrups.

Hot-rolled ribbed steel rebars (S400) were used for the longitudinal and transversal reinforcement. The commercial diameters of these rebars were: $6,8,10,12$, 16 and $20 \mathrm{~mm}$ (Fig. 1). The concrete cover was $2 \mathrm{~cm}$.

Table 1 summarizes some relevant geometrical, physical and mechanical properties of each test beam, namely: the effective depth $(d)$ of the cross-section, the average LWAC compressive strength $\left(f_{l c}\right)$ and dry density $\left(\delta_{l}\right)$, the area of longitudinal tensile reinforcement $\left(A_{S}\right)$ and the reinforcement ratios $\rho$.

The beams were classified into 3 series, corresponding to a given range of concrete strength.

For the production of LWAC, two types of Portland cement CEM I 42.5R and CEM II/B-L32.5N (with specific gravity 3.14 and 3.04 and fineness 385 and $462 \mathrm{~m}^{2} / \mathrm{kg}$, respectively) and two mineral additions, limestone

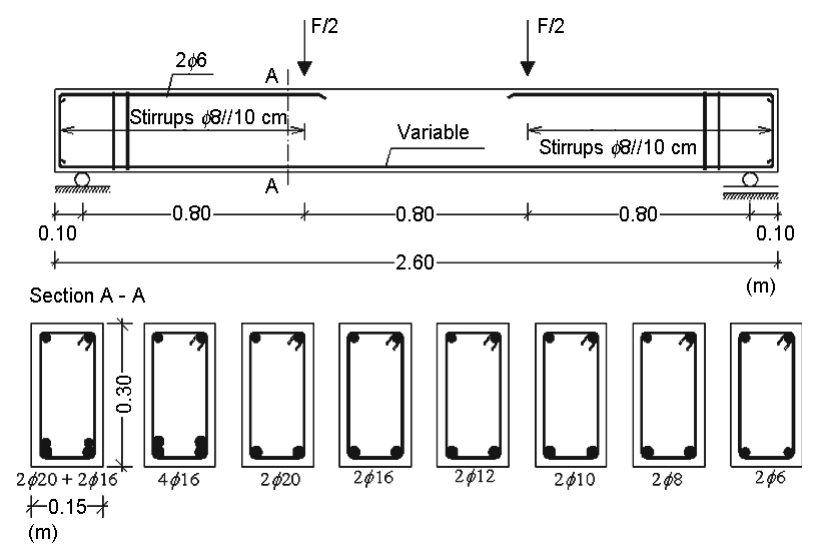

Fig. 1. Geometry and details of test beams 
Table 1. Properties of test beams

\begin{tabular}{|c|c|c|c|c|c|}
\hline $\begin{array}{l}\text { Beam series } \\
\left(f_{l c}-\rho\right)\end{array}$ & $\begin{array}{c}f_{l c} \\
\mathrm{MPa} \\
\end{array}$ & $\begin{array}{c}\delta_{l} \\
\mathrm{~kg} / \mathrm{m}^{3}\end{array}$ & $\begin{array}{c}A_{s} \\
\mathrm{~cm}^{2}\end{array}$ & $\begin{array}{c}d \\
\mathrm{~cm}\end{array}$ & $\begin{array}{c}\rho=A_{s} / b d \\
\% \\
\end{array}$ \\
\hline $1(23.5-0.13)$ & 23.5 & 1659 & $0.56(2 \phi 6)$ & 27.7 & 0.13 \\
\hline $1(22.8-0.24)$ & 22.8 & 1685 & $1.01(2 \phi 8)$ & 27.6 & 0.24 \\
\hline $1(22.0-0.38)$ & 22.0 & 1667 & $1.58(2 \phi 10)$ & 27.5 & 0.38 \\
\hline $1(22.4-0.55)$ & 22.4 & 1651 & $2.26(2 \phi 12)$ & 27.4 & 0.55 \\
\hline $1(28.5-0.99)$ & 28.5 & 1659 & $4.02(2 \phi 16)$ & 27.2 & 0.99 \\
\hline $2(45.1-0.13)$ & 45.1 & 1802 & $0.56(2 \phi 6)$ & 27.7 & 0.13 \\
\hline $2(42.1-0.24)$ & 42.1 & 1807 & $1.01(2 \phi 8)$ & 27.6 & 0.24 \\
\hline $2(47.1-0.38)$ & 47.1 & 1809 & $1.58(2 \phi 10)$ & 27.5 & 0.38 \\
\hline $2(49.2-0.55)$ & 49.2 & 1827 & $2.26(2 \phi 12)$ & 27.4 & 0.55 \\
\hline 2(43.9-0.99) & 43.9 & 1788 & $4.02(2 \phi 16)$ & 27.2 & 0.99 \\
\hline $2(47.0-1.55)$ & 47.0 & 1791 & $6.28(2 \phi 20)$ & 27.0 & 1.55 \\
\hline $2(43.0-2.03)$ & 43.0 & 1790 & $8.04(4 \phi 16)$ & 26.4 & 2.03 \\
\hline $3(52.1-0.13)$ & 52.1 & 1867 & $0.56(2 \phi 6)$ & 27.7 & 0.13 \\
\hline $3(51.2-0.38)$ & 51.2 & 1879 & $1.58(2 \phi 10)$ & 27.5 & 0.38 \\
\hline $3(52.4-0.55)$ & 52.4 & 1869 & $2.26(2 \phi 12)$ & 27.4 & 0.55 \\
\hline $3(55.3-0.99)$ & 55.3 & 1910 & $4.02(2 \phi 16)$ & 27.2 & 0.99 \\
\hline $3(53.4-1.55)$ & 53.4 & 1877 & $6.28(2 \phi 20)$ & 27.0 & 1.55 \\
\hline $3(60.4-2.03)$ & 60.4 & 1953 & $8.04(4 \phi 16)$ & 26.4 & 2.03 \\
\hline $3(51.6-2.69)$ & 51.6 & 1867 & $\begin{array}{c}10.30 \\
(2 \phi 16+2 \phi 20)\end{array}$ & 25.5 & 2.69 \\
\hline
\end{tabular}

powder and microsilica (with specific gravity 2.72 and 2.17 and fineness 509 and $130 \mathrm{~m}^{2} / \mathrm{kg}$, respectively), were used. A superplasticizer in liquid form was used (specific gravity of 1.20). Natural normal-weight sand (Sand 0/5) was used, with a specific gravity of 2.61 and a fineness modulus of 2.705 . The coarse aggregate includes only expanded clay (Leca 4/12) with a specific gravity of 1.31 , fineness modulus of 5.958 and water absorption of $14.1 \%$ at $24 \mathrm{~h}, 3.98 \%$ at $30 \mathrm{~min}$ and $3.56 \%$ at $15 \mathrm{~min}$.

Table 2 gives, for each series of beams, the mix proportions of the LWAC produced in the laboratory.

The slump test was between 8 and $12 \mathrm{~cm}$. For each beam, at least three $15 \mathrm{~cm}$ cube specimens were molded and cured in the same conditions as the correspondent beams. Compressive tests (after 28 days) were carried out to obtain the average value of the compressive strength $\left(f_{l c}\right)$.

Tensile tests were carried out on samples of steel tensile reinforcement bars used in the beams. Table 3 shows the results of the tests, namely the average yielding stress $\left(f_{y}\right)$, the first yield strain values $\left(\varepsilon_{y}\right)$ and the stress corresponding to the maximum force $\left(f_{t}\right)$. The yield strain $\left(\varepsilon_{y}\right)$ was calculated assuming linear relationship (Hooke's law) and Young's Modulus $\left(E_{s}\right)$ of $200 \mathrm{GPa}$.

Figure 2 illustrates the beam in test position, including the location of the external measuring instruments. An external grid of Demec targets placed on one side of the beam, between the load application points, was used to measure the strains along the height of the central sections. Resistance strain gauges were fixed to the longitudinal tensile bars to measure the evolution of strains at mid-span of the beams. The level of load
Table 2. Mix design of LWAC

\begin{tabular}{|c|c|c|c|c|}
\hline & & \multicolumn{3}{|c|}{$\begin{array}{c}\text { Mix design } \\
\text { (content per cubic meter) }\end{array}$} \\
\hline \multicolumn{2}{|c|}{ Component } & Series 1 & Series 2 & Series 3 \\
\hline \multirow{2}{*}{$\begin{array}{l}\text { Portland } \\
\text { cement (kg) }\end{array}$} & $\begin{array}{l}\text { CEM } \\
\text { II/B-L32.5N }\end{array}$ & 335 & - & - \\
\hline & CEM I 42.5R & - & 445 & 494 \\
\hline \multirow{2}{*}{$\begin{array}{l}\text { Mineral } \\
\text { addition (kg) }\end{array}$} & $\begin{array}{l}\text { Limestone } \\
\text { powder }\end{array}$ & - & - & 35 \\
\hline & Microsilica & - & - & 43 \\
\hline \multicolumn{2}{|c|}{ Superplasticizer (1) } & 1.34 & 5.34 & 9.88 \\
\hline \multicolumn{2}{|l|}{ Water (1) } & 174 & 146 & 153 \\
\hline \multicolumn{2}{|c|}{$\begin{array}{l}\text { Natural normal-weight } \\
\text { sand } 0 / 5(\mathrm{~kg})\end{array}$} & 841 & 756 & 775 \\
\hline \multicolumn{2}{|c|}{$\begin{array}{l}\text { Lightweight coarse aggregate } \\
\text { (expanded clay) }(\mathrm{kg}) \\
D_{\text {máx }}=12.7 \mathrm{~mm} \\
\end{array}$} & 463 & 501 & 426 \\
\hline \multicolumn{2}{|c|}{ water-binder ratio (in mass) } & 0.52 & 0.33 & 0.29 \\
\hline \multicolumn{2}{|c|}{$\begin{array}{l}\text { Density of fresh concrete } \\
\left(\mathrm{kg} / \mathrm{m}^{3}\right)\end{array}$} & 1814 & 1853 & 1935 \\
\hline
\end{tabular}

Table 3. Tensile test results for steel test specimens

\begin{tabular}{lccccccc}
\hline $\begin{array}{l}\text { Diameter } \\
\mathrm{mm}\end{array}$ & $\begin{array}{c}f_{y} \\
\mathrm{MPa}\end{array}$ & $\begin{array}{c}\varepsilon_{y} \\
10^{-6}\end{array}$ & $\begin{array}{c}f_{t} \\
\mathrm{MPa}\end{array}$ & $\begin{array}{c}\text { Diameter } \\
\mathrm{mm}\end{array}$ & $\begin{array}{c}f_{y} \\
\mathrm{MPa}\end{array}$ & $\begin{array}{c}\varepsilon_{y} \\
10^{-6}\end{array}$ & $\begin{array}{c}f_{t} \\
\mathrm{MPa}\end{array}$ \\
\hline$\phi 6$ & 503 & 2515 & 536 & $\phi 12$ & 534 & 2672 & 642 \\
\hline$\phi 8$ & 550 & 2750 & 670 & $\phi 16$ & 575 & 2876 & 679 \\
\hline$\phi 10$ & 565 & 2825 & 684 & $\phi 20$ & 572 & 2860 & 668 \\
\hline
\end{tabular}

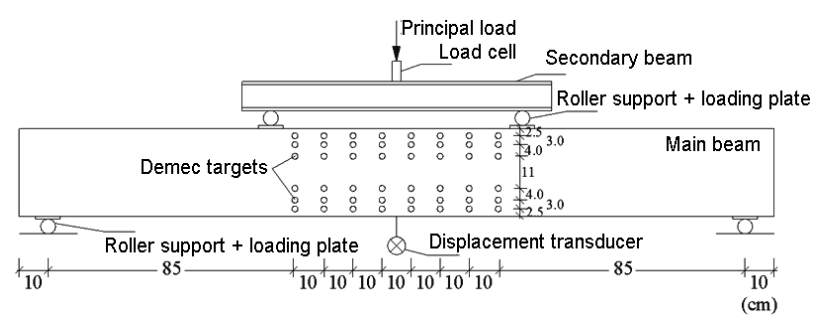

Fig. 2. Set-up for testing beam specimen

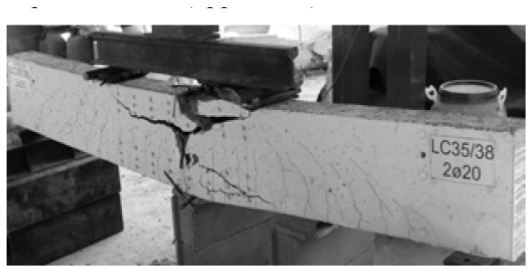

Fig. 3. Test beam after failure

applied to the beam was measured by using a load cell. A displacement transducer placed at mid span of the beam measured the vertical displacements. Tests were performed under deformation control.

Figure 3 shows one of the test beams at the end of the test, with the failure section in the central region. Except the first beam of each series, with the lower longitudinal tensile reinforcement ratio, all beams failed in 
pure flexion (on the central zone) by crushing of concrete on the compression side (upper face).

\section{Experimental curves}

Figures 4(a) to 4(c) represent, for each series of beams, the total load $(P)$ - deflection $(\delta)$ curves plotted from the experimental readings recorded during the tests. $P$ and $\delta$ parameters are related to the level of load applied and to the deflection at the mid-span of the beams.

For the first beam of each series, with the lowest tensile reinforcement ratio, the yielding of the reinforcement occurred suddenly after the first concrete crack occurred. Because of the limitation of the measuring instruments, it was not possible for these beams to record accurately the readings until the effective failure of the steel bars. For all the remaining beams, failure occurred by the crushing of the compressive concrete in the section.

A global analysis of the graphs in Figures 4(a) to 4(c) reveals that, for a given range of concrete strengths, the ductility, or the deformation capacity of the beam after the yielding of the longitudinal tensile reinforcement, and with approximately the same load level, tends to decrease as the area of the tensile reinforcement increases. The above tendency was already expected and has been previously reported on studies with NWAC and LWAC
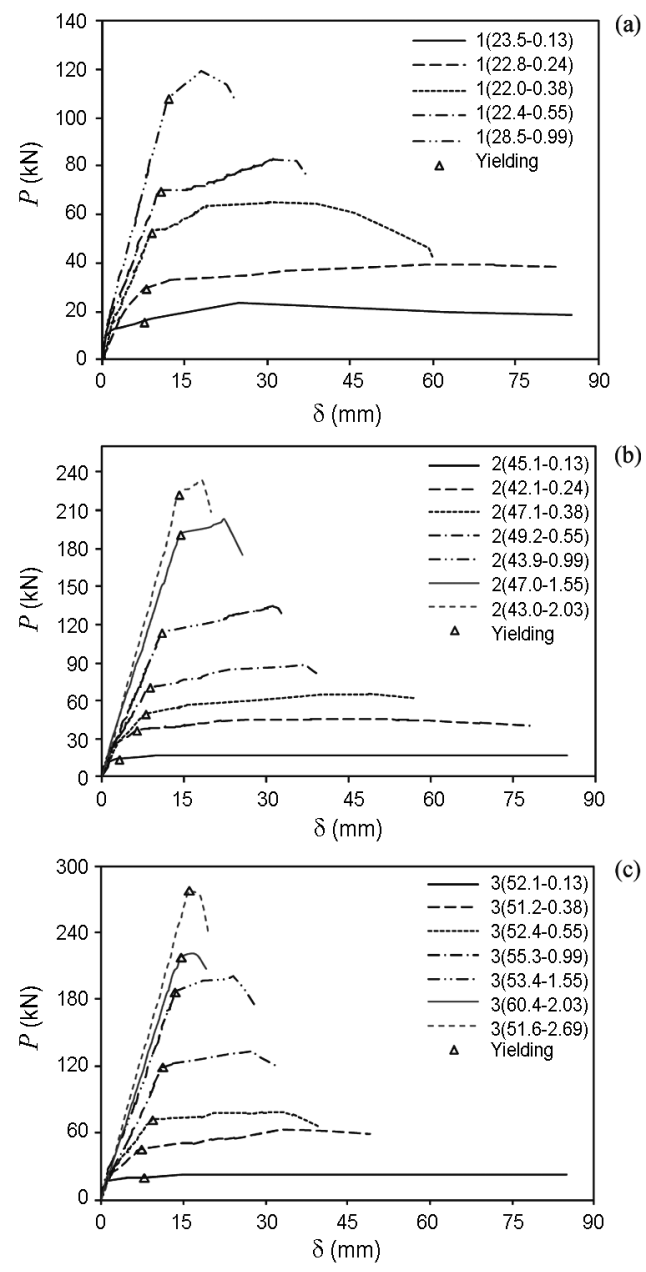

Fig. 4. $P-\delta$ curves: a) Series 1 ; b) Series 2 ; c) Series 3 beams, both NS and HS concrete (Shin et al. 1989; Ahmad, Barker 1991; Ahmad, Batts 1991; Bernardo, Lopes 2003, 2004).

Figures 5(a) to 5(c) give the experimental Moment $(M)$ - Curvature $(\chi)$ curves for each tested beam.

The moments in the central zone are related with the load recorded during the tests. The curvatures in the central zone (failure zone) were determined from the experimental diagrams of the strains along the height of the sections, recorded from the external grid of Demec targets (Fig. 2). By using a Demec strain gauge, the measurement of the distance between two consecutive Demec targets was manually performed for each level of Demec targets along the height of the sections and also for some loading levels (tests were temporary stopped to perform this measurement). The experimental strains along the height of the sections (for each level of Demec targets) were calculated knowing the initial distance between Demec targets $(10 \mathrm{~cm})$ and the variation of this distance for each loading level. The experimental diagrams of the strains were obtained by simple regression analysis.

Some $M-\chi$ curves don't include a descending branch. This could be due to the limited opening of the Demec strain gauge. In fact, in the final phase of testing (before failure occurred), such a large crack opened up
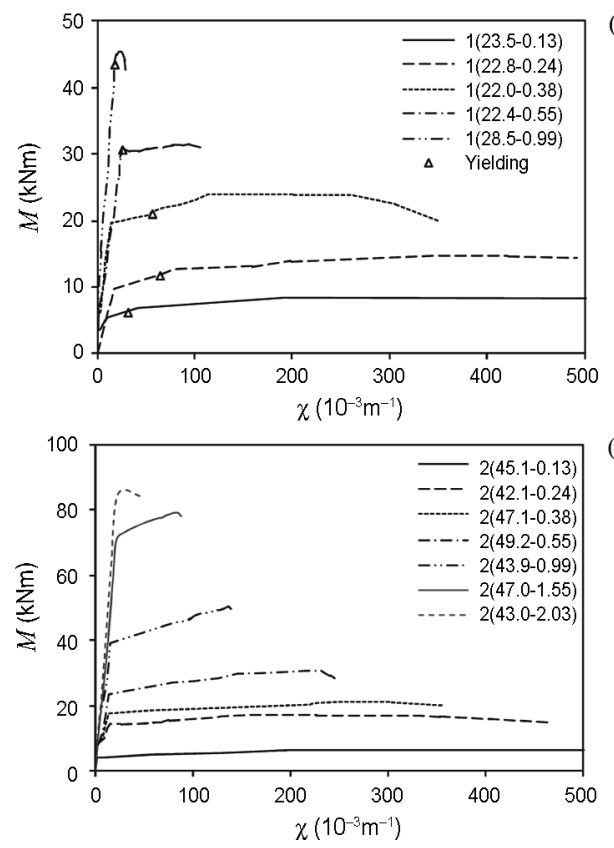

(b)

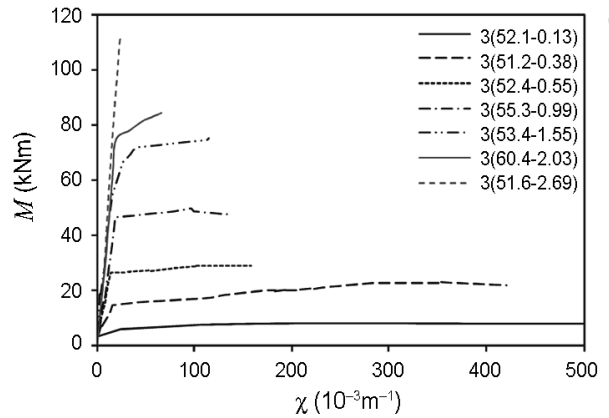

Fig. 5. $M-\chi$ curves: a) Series 1 ; b) Series 2; c) Series 3 
in the failure section of some beams that the distance between the surrounding Demec targets in the tension zone could no longer be measured with the Demec strain gauge. This meant that the final part of some $M-\chi$ curves may be partially incomplete. This is particularly true for the beams with the lowest tensile reinforcement ratio because the ultimate deformations of such beams are very high.

Analysis of the curves in Figures 5(a) to 5(c) shows that, in general, the shape of the $M-\chi$ curves is bilinear. This observation agrees with previous studies with NWAC beams (for example, Bernardo, Lopes 2003, 2004).

Table 4 gives the experimental values for the yield load $\left(P_{y}\right)$, maximum (resistant) load $\left(P_{r}\right)$, corresponding deflections $\left(\delta_{y}\right.$ and $\left.\delta_{r}\right)$, yield moment $\left(M_{y}\right)$, maximum (resistant) moment $\left(M_{r}\right)$ and corresponding curvatures $\left(\chi_{y}\right.$ and $\left.\chi_{r}\right)$, found for each tested beam. The cracking load and cracking moment are not included in Table 4. In fact, in the experimental behavioral curves and for some beams, it was not possible to clearly visualize the transition between non-cracked stage and cracked stage. These beams have probably some degree of premature cracking, due to the handling and due to the higher brittleness of the LWAC. For the first beam of each series and due to the referred previously, only some reliable information is given in Table 4 .

The yield load $\left(P_{y}\right)$ was calculated comparing the experimental records of the strains in the longitudinal tensile reinforcements with the average values for yielding strains (Table 3 ). The yield deflection $\left(\delta_{y}\right)$ is computed from a linear interpolation of the experimental values recorded for the load and the deflection, obviously first knowing the yield load $\left(P_{y}\right)$ for each beam. The yield moment $\left(M_{y}\right)$ was obtained statically using the known experimental $P_{y}$ value. The yield curvature $\left(\chi_{y}\right)$ is computed from a linear interpolation of the experimental values obtained for the moments and curvatures, obviously first knowing the yield moment for each beam.

\section{Flexural ductility}

\subsection{Ductility indexes}

According to several authors, flexural ductility should be based on the inelastic deformation state of the beam. In this study, two ductility indexes are used. The first index, termed the deflection ductility index $\left(\mu_{\delta}\right)$, refers to the deflection at mid span recorded during the tests on the beams, and the second one, termed curvature ductility index $\left(\mu_{\gamma}\right)$, concerns the rotation of the section per unit length in the central zone of the beams. The ductility indexes are calculated as follows:

$$
\begin{aligned}
& \mu_{\delta}=\frac{\delta_{u}}{\delta_{y}} ; \\
& \mu_{\chi}=\frac{\chi_{u}}{\chi_{y}} .
\end{aligned}
$$

These indexes quantify the extent of the deformation region that starts at the point corresponding to the yielding load and continues to the point corresponding to the ultimate load $\left(\delta_{u}\right.$ and $\left.\chi_{u}\right)$. The two indexes defined above were also used in previous studies (for example, Shin et al. 1989; Ahmad, Barker 1991; Shehata I., Shehata L. 1996; Bernardo, Lopes 2003, 2004).

\begin{tabular}{|c|c|c|c|c|c|c|c|c|}
\hline Beam & $P_{y} \mathrm{kN}$ & $P_{r} \mathrm{kN}$ & $\delta_{y} \mathrm{~mm}$ & $\delta_{r} \mathrm{~mm}$ & $M_{y} \mathrm{kNm}$ & $M_{r} \mathrm{kNm}$ & $\chi_{y} 10^{-3} \mathrm{~m}^{-1}$ & $\chi_{r} 10^{-3} \mathrm{~m}^{-1}$ \\
\hline $1(23.5-0.13)$ & 15.9 & $\approx 23.8$ & 7.6 & - & 6.34 & $\approx 8.5$ & 31.2 & - \\
\hline $1(22.8-0.24)$ & 29.7 & 39.3 & 8.0 & 71.1 & 11.88 & 14.7 & 64.0 & 421.3 \\
\hline $1(22.0-0.38)$ & 52.9 & 64.2 & 9.0 & 39.0 & 21.15 & 24.0 & 56.2 & 113.4 \\
\hline $1(22.4-0.55)$ & 70.0 & 82.9 & 10.7 & 31.0 & 30.79 & 31.4 & 25.6 & 94.9 \\
\hline $1(28.5-0.99)$ & 108.4 & 119.5 & 12.1 & 18.0 & 43.61 & 45.4 & 17.7 & 22.4 \\
\hline $2(45.1-0.13)$ & 14.1 & $\approx 17.3$ & 3.1 & - & 5.61 & $\approx 6.2$ & 130.6 & - \\
\hline $2(42.1-0.24)$ & 37.0 & 45.5 & 6.3 & 47.7 & 14.83 & 16.9 & 59.6 & 249.1 \\
\hline $2(47.1-0.38)$ & 50.0 & 64.9 & 7.9 & 48.7 & 18.55 & 21.1 & 54.8 & 303.6 \\
\hline $2(49.2-0.55)$ & 71.1 & 87.7 & 8.7 & 37.3 & 25.13 & 30.6 & 46.4 & 232.2 \\
\hline $2(43.9-0.99)$ & 114.1 & 134.4 & 10.9 & 31.4 & 42.50 & 50.3 & 48.1 & 136.2 \\
\hline $2(47.0-1.55)$ & 191.5 & 202.7 & 14.3 & 22.4 & 73.26 & 79.1 & 31.3 & 84.2 \\
\hline $2(43.0-2.03)$ & 223.0 & 232.3 & 14.0 & 20.0 & 84.93 & 84.9 & 22.9 & 22.9 \\
\hline $3(52.1-0.13)$ & 20.2 & $\approx 22.5$ & 7.8 & - & 7.37 & $\approx 8.2$ & 108.0 & - \\
\hline $3(51.2-0.38)$ & 45.7 & 62.4 & 7.4 & 33.1 & 16.37 & 23.0 & 67.5 & 284.3 \\
\hline $3(52.4-0.55)$ & 72.1 & 79.0 & 9.4 & 32.2 & 26.80 & 29.1 & 31.9 & 121.5 \\
\hline $3(55.3-0.99)$ & 119.6 & 132.7 & 11.2 & 27.5 & 47.76 & 49.7 & 49.9 & 96.3 \\
\hline $3(53.4-1.55)$ & 186.9 & 200.1 & 13.5 & 23.9 & 72.09 & 75.1 & 41.8 & 115.0 \\
\hline $3(60.4-2.03)$ & 218.2 & 220.6 & 14.6 & 17.2 & 77.99 & 84.2 & 33.4 & 66.2 \\
\hline $3(51.6-2.69)$ & 278.3 & 279.1 & 16.0 & 16.3 & 110.61 & 111.6 & 23.2 & 23.8 \\
\hline
\end{tabular}

Table 4 . Key points of $P-\delta$ and $M-\chi$ curves 
To compute the ductility indexes, it is necessary to define the point corresponding to the ultimate load in the experimental curves presented in Section 3. In general, this point corresponds to the one from which the beam, with the reinforcement yielding, ceases to support substantial loads. Such a definition is subjective and can be hard to apply due to the diversity of shapes found for the final part of the experimental curves (Section 3).

A detailed discussion about the several criteria used in earlier research works to define the ultimate point was previously presented by Bernardo and Lopes (2003). The level of ductility of each beam (calculation value, not the real value) will depends on the criterion used by the authors. Some criteria include the initial part of the descending branch of the experimental curves. Other criteria includes only the entire "horizontal landing" of the experimental curves after the yielding of the longitudinal reinforcement. In both cases, the levels of ductility will not be very different.

Because $M-\chi$ curves (Fig. 5(a) to 5(c)) generally do not present an accurate descending branch, Bernardo and Lopes (2003) established a simple criterion to quantify a "conventional" ultimate value for the deformations, considered valid for a comparative analysis of ductility between the test beams. The criterion by these authors was that of making the ultimate point on the experimental curves correspond to the point of intersection between the final part of the curve with a horizontal line that across at the point where the reinforcement start to yield. If no intersection is found to occur between the aforementioned line and the experimental curve, the ultimate point is simply ascribed to the ultimate point on the curve. This criterion is illustrated in Figures 6(a) and 6(b) and was also used in this study. Figure 6 shows that the criterion consider only the entire "horizontal landing" of the behavioral curve after the yielding of the longitudinal reinforcement.

Table 5 presents the experimental values for the yield deflection $\left(\delta_{y}\right)$, ultimate deflection $\left(\delta_{u}\right)$, yield curvature $\left(\chi_{y}\right)$ and ultimate curvature $\left(\chi_{u}\right)$, and also the experimental values obtained for the deflection ductility index $\left(\mu_{\delta}\right)$ and the curvature ductility index $\left(\mu_{\gamma}\right)$. The first beam of each series are not included in Table 5 because the last part of their experimental curves is not reliable (Section 3).

Table 5 also present the average compressive strength of the concrete $\left(f_{l c m}\right)$ for each series of beams, to be used latter (Section 4.2).

Table 5 shows that, for the same beams, the range of values for the ductility indexes (deflection and curvature) are somewhat different, mainly for the beams with lower longitudinal tensile reinforcement ratio. As previously referred (Section 3), this is probably due to the limited opening of the Demec strain gauge.

Another aspect from Table 5 refers to Beams 3(55.30.99 ) and 3(53.4-1.55). The corresponding curvature ductility index (2.7 and 2.8, respectively) seems to be unreasonable because it is expected that, the higher longitudinal tensile reinforcement ratio, the lower the
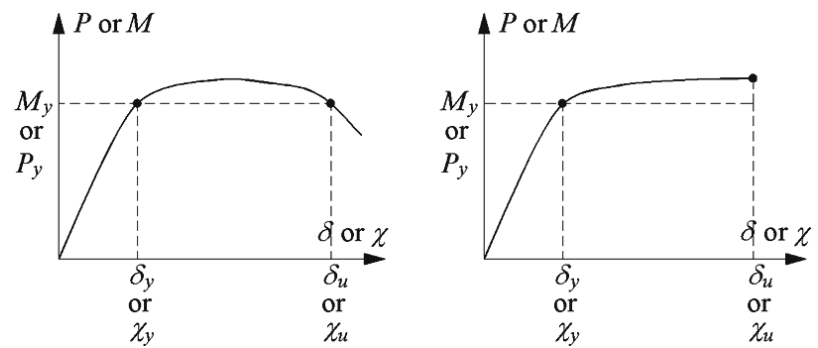

Fig. 6. Criterion: a) with intersection; b) no intersection

Table 5. Experimental values of ductility indexes

\begin{tabular}{|c|c|c|c|c|c|c|c|}
\hline Beam & $\begin{array}{l}f_{l c m} \\
\mathrm{MPa}\end{array}$ & $\begin{array}{c}\delta_{y} \\
\mathrm{~mm}\end{array}$ & $\begin{array}{c}\delta_{u} \\
\mathrm{~mm}\end{array}$ & $\begin{array}{c}\chi_{y} \\
10^{-3} \mathrm{~m}^{-1}\end{array}$ & $\begin{array}{c}\chi_{u} \\
10^{-3} \mathrm{~m}^{-1}\end{array}$ & $\mu_{\delta}$ & $\mu_{\chi}$ \\
\hline $1(22.8-0.24)$ & \multirow{4}{*}{23.9} & 8.0 & 82.9 & 64.0 & 491.5 & 10.4 & 7.9 \\
\hline$\overline{1(22.0-0.38)}$ & & 9.0 & 53.4 & 56.2 & 327.2 & 5.9 & $\overline{5.8}$ \\
\hline$\overline{1(22.4-0.55)}$ & & 10.7 & 37.2 & 25.6 & 107.8 & 3.5 & 4.2 \\
\hline$\overline{1(28.5-0.99)}$ & & 12.1 & 24.0 & 17.7 & 28.8 & 2.0 & 1.6 \\
\hline $2(42.1-0.24)$ & \multirow{6}{*}{$45.4-$} & 6.3 & 78.0 & 59.6 & 463.6 & 12.4 & $\overline{7.8}$ \\
\hline$\overline{2(47.1-0.38)}$ & & 7.9 & 57.1 & 54.8 & 355.5 & 7.2 & 6.5 \\
\hline $2(49.2-0.55)$ & & 8.7 & 39.4 & 46.4 & 245.4 & 4.5 & 5.3 \\
\hline$\overline{2(43.9-0.99)}$ & & 10.9 & 32.9 & 48.1 & 139.9 & 3.0 & 2.9 \\
\hline$\overline{2(47.0-1.55)}$ & & 14.3 & 23.7 & 31.3 & 88.6 & 1.7 & 2.8 \\
\hline $2(43.0-2.03)$ & & 14.0 & 19.1 & 22.9 & 48.4 & 1.4 & 2.1 \\
\hline $3(51.2-0.38)$ & \multirow{6}{*}{$54.1-$} & 7.4 & 49.0 & 67.5 & 420.4 & 6.7 & 6.2 \\
\hline $3(52.4-0.55)$ & & 9.4 & 36.7 & 31.9 & 158.1 & 3.9 & 5.0 \\
\hline $3(55.3-0.99)$ & & 11.2 & 32.1 & 49.9 & 134.1 & 2.9 & 2.7 \\
\hline$\overline{3(53.4-1.55)}$ & & 13.5 & 26.3 & 41.8 & 115.0 & 2.0 & 2.8 \\
\hline $3(60.4-2.03)$ & & 14.6 & 17.6 & 33.4 & 66.2 & 1.2 & 2.0 \\
\hline$\overline{3(51.6-2.69)}$ & & 16.0 & 16.4 & 23.2 & 26.2 & 1.0 & 1.1 \\
\hline
\end{tabular}

ductility. As referred in Section 3, the curvatures in the central zone (failure zone) were determined from the experimental diagrams of the strains along the height of the sections. The measurement of the strains was manually performed only for some loading levels. Then, it was not always possible to measure the strains near the instant of the beam failure. As a consequence, some variability exists for the ultimate curvatures among the tested beams. However, this problem seems to not have a high influence in the results, since the general trends observed with the curvature ductility index agrees with the same ones observed with the deflection ductility index (as will be shown in Sections 4.2 and 4.3).

\subsection{Influence of the concrete strength}

In order to analyze the influence of the concrete compressive strength on the ductility, Table 6 groups the beams as a function of their reinforcement ratios $(\rho)$ and presents the average longitudinal tensile reinforcement ratios values $\left(\rho_{m}\right)$ for each group. Only groups with 3 beams at least are presented.

A global analysis of Table 6 shows that the ductility indexes seem to increase slightly with increasing compressive strength of the concrete. 
Table 6. Beams groups with similar reinforcement ratio

\begin{tabular}{|c|c|c|c|c|c|}
\hline Group & Beam & $\begin{array}{c}\rho_{m} \\
\%\end{array}$ & $\begin{array}{c}f_{l c} \\
\mathrm{MPa}\end{array}$ & $\mu_{\delta}$ & $\mu_{\chi}$ \\
\hline \multirow{3}{*}{ I } & $1(22.0-0.38)$ & \multirow{3}{*}{0.38} & 22.0 & 5.9 & 5.8 \\
\hline & $\overline{2(47.1-0.38)}$ & & 47.1 & 7.2 & 6.5 \\
\hline & $\overline{3(51.2-0.38)}$ & & 51.2 & 6.7 & 6.2 \\
\hline \multirow{3}{*}{ II } & $1(22.4-0.55)$ & \multirow{3}{*}{0.55} & 22.4 & 3.5 & 4.2 \\
\hline & $\overline{2(49.2-0.55)}$ & & 49.2 & 4.5 & 5.3 \\
\hline & $\overline{3(52.4-0.55)}$ & & 52.4 & 3.9 & 5.0 \\
\hline \multirow{3}{*}{ III } & $1(28.5-0.99)$ & \multirow{3}{*}{0.99} & 28.5 & 2.0 & 1.6 \\
\hline & $\overline{2(43.9-0.99)}$ & & 43.9 & 3.0 & 2.9 \\
\hline & $\overline{3(55.3-0.99)}$ & & 55.3 & 2.9 & 2.7 \\
\hline
\end{tabular}

The graphs in Figures 7(a) and 7(b) show the evolution of the ductility indexes ( $\mu_{\delta}$ and $\mu_{\chi}$, respectively) with the concrete compressive strengths $\left(f_{l c}\right)$ for Groups I, II and III (Table 6). The graphs also include a line of tendency calculated in linear regression. The tendencies observed graphically confirm the previous conclusions based on the values from Table 6: for an approximately constant longitudinal tensile reinforcement ratio, the ductility of the beams increases slightly with increasing concrete compressive strength.

The above tendency agree with the one observed by Bernardo and Lopes $(2003,2004)$ based on a global analysis of NWAC beams, using the same criterion to define the ultimate point of the experimental curves (Fig. 6). These results also confirm the findings of some authors with other criterion to define the ultimate point of the experimental curves (for example, Shin et al. 1989). However, they contradict those of other authors (for example, Ahmad, Barker 1991; Shehata I., Shehata L. 1996).

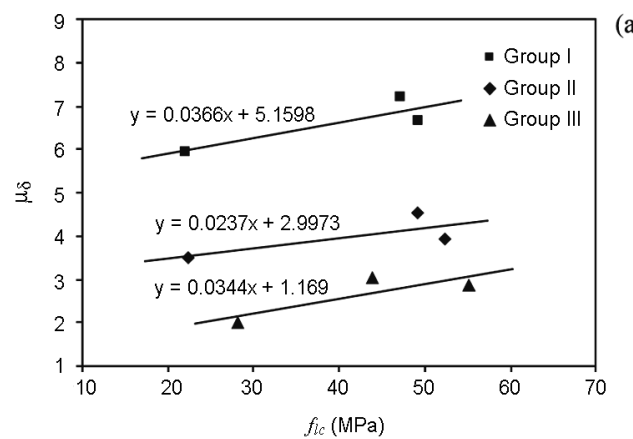

(a)

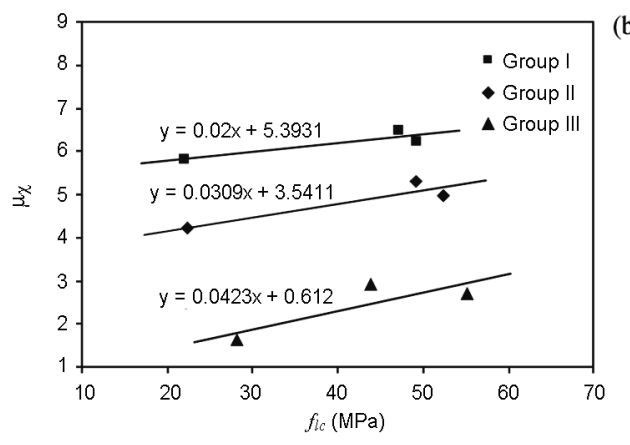

Fig. 7. Influence of concrete strength on ductility: a) index $\mu_{\delta}$; b) index $\mu_{\chi}$
The trend observed in this section has a physical explanation. The flexural behavior of the beams is, in fact, governed by the mechanical percentage of steel reinforcement $\left(\rho f_{y} / f_{c}\right)$, instead of the geometrical percentage $(\rho)$. Therefore, the ductility increases as the mechanical percentage of steel decreases. Hence, beams with a lower longitudinal reinforcement ratio and higher concrete compressive strength can have higher ductility than beams with a higher longitudinal reinforcement ratio and lower concrete compressive strength.

\subsection{Influence of the reinforcement ratio}

Analysis of the influence of the longitudinal tensile reinforcement ratio on the flexural ductility requires the beams with similar or equal concrete compressive strength to be grouped together. Then, Table 5 can be used for this section.

The analysis of the values obtained for the ductility indexes in Table 5 seems to shows that, for each group of beams, the ductility tends to decrease with increasing longitudinal reinforcement ratio. This tendency seems to be enhanced for the beams with low longitudinal tensile reinforcement ratio. This behavior, already expected, may be explained by a fall in the ultimate deformation of the element with an increase in the longitudinal tensile reinforcement ratio, thereby causing a loss of ductility.

The above tendency agree with the one observed by other authors (Bernardo, Lopes 2003, 2004; Shin et al. 1989; Ahmad, Barker 1991; Shehata I., Shehata L. 1996).

Figures 8(a) and 8(b) present the graphs showing the evolution of the ductility indexes as a function of the longitudinal tensile reinforcement ratio $\rho$. The graphs of Figure 8 also include a potential tendency curve, which would perfectly fit the tendency of the results.
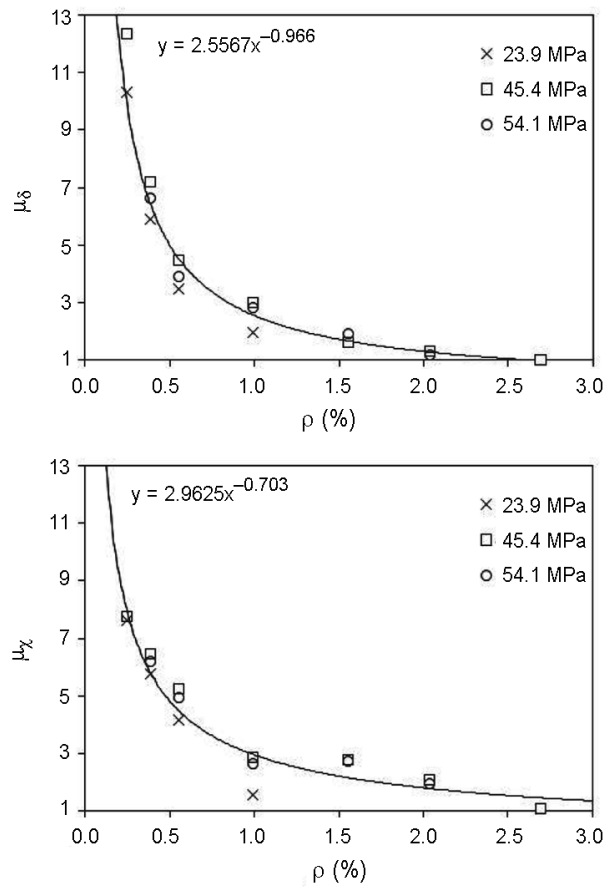

(b)

Fig. 8. Influence of reinforcement ratio on ductility: (a) index $\mu_{\delta}$, (b) index $\mu_{\chi}$ 
In the previous section, it was shown that the influence of the compressive strength of the concrete on ductility is slight, so the graphs in Figures 8(a) and 8(b) include the results for all groups of beams, regardless of concrete strength. However, the different groups of beams are identified on the graphs by their respective average concrete compressive strength.

Analysis of the graphs in Figures 8(a) and 8(b) confirms the ductility reduction as the longitudinal tensile reinforcement ratio increases, as observed before.

The graph from Figure 8(a) also shows a high reduction in deflection ductility index inasmuch as the longitudinal tensile reinforcement ratio increases to a value of approximately $\rho \approx 1.5-2.0 \%$. After these values, the graphs suggest that the deflection ductility indexes for the beams under study are very small and tend slowly towards the unity (beams without ductility), almost independent of concrete strength since in these zones the values seems to be less dispersed.

These findings suggest that the increment in the ductility, with increasing concrete strength (Section 4.2), tends to fall with increasing longitudinal reinforcement ratio.

For the graph from Figure 8(b) and for curvature ductility index, the previous limits seem to be somewhat higher. However, it should be noted that the limits for deflection ductility index should be considered more reliable due to the limited opening of the Demec strain gauge (as discussed in Section 3).

These results also confirm the findings from other authors for NWAC beams, both NS and HS concrete, such as Shehata I. and Shehata L. (1996) and Bernardo and Lopes $(2003,2004)$. However, the limits for the tensile reinforcement ratio reported in the last two references, by studying the deflection ductility index, were $\rho \approx 3.0 \%$. These limits are somewhat higher than those previously observed for the beams tested in this study.

The previous observation seems to show that the upper limit for the longitudinal tensile reinforcement ratio compatible with good ductility level is somewhat smaller for LWAC beams, when compared with NWAC beams.

A comparative analysis of the results presented in this section and those in the previous one leads to the conclusion that the parameter with the most influence on the ductility of the beams, from the two studied, is the longitudinal tensile reinforcement ratio.

\section{Comparative analyses with codes requirements}

\subsection{Codes requirements}

This study aim to analyze some simplest design rules intended for the assurance of enough ductility in LWAC beams, in the light of the test results of the experimental program described in this paper. This analysis will only focus the limitation of the amount of longitudinal tensile reinforcement, since this approaching is very traditional in codes of practice. In fact, for beams with no special ductility requirements, and as far as beams under sim- ple bending are concerned, designers usually focus on the limitation of the amount of tensile longitudinal steel reinforcement, among other simple rules.

This approach was also used in previous studies focused on beams ductility (Bernardo, Lopes 2003, 2004, 2009 for beams under flexure).

By fixing a minimal amount of tensile longitudinal reinforcement the codes of practice aims to prevent the premature and sudden failure of the steel reinforcement that might occur when the first concrete crack would appear. This failure is premature because it occurs for very low level loadings.

The codes of practice also fix a maximum amount of longitudinal tensile reinforcement. The aim is to ensure a minimum level of ductility, since an exaggerated amount of steel reinforcement might conduce to a fragile failure by crushing of the concrete, even before the steel reaches the yielding strain.

The equations to compute the minimum and maximum longitudinal tensile reinforcement $\left(\rho_{\min }\right.$ and $\left.\rho_{\max }\right)$, from the studied codes of practice, are summarized in Table 7. For CEB (1990) (Model Code 1990 - MC90), Section 9.2.2.1 was applied. Fib (2000) (recommended extension to MC90 for LWAC) do not incorporate information about required changes on equations from MC90 to compute $\rho_{\min }$ and $\rho_{\max }$ in order to be applied for LWAC beams. For Fib (2010) (Model Code 2010 MC2010), Section 7.13.5.2 was applied. It should be noted that the $f_{l c}$ values from Table 1 (referred to $15 \mathrm{~cm}$ cubic samples) were previously converted to cylindrical samples, using Table 5.1.4 from Fib 2010, for LWAC.

The requirements from NP EN1992-1-1 2010 (Eurocode 2 - EC2) are the same as for Fib 2010 (see Sections 9.2.1.1 and 11.3.1 from NP EN1992-1-1 2010).

For ACI 318 (2011), Sections 10.5.1, 10.2.5 and Commentary R10.3.5 were applied. In Section 10.2.5, ACI 318 (2011) states that for RC flexural members, the net tensile strain in the extreme tension steel, $\varepsilon_{t}$, at nominal strength shall not be less than 0.004 . This limit provides minimum ductile behavior (the sections are mainly tension-controlled). In Commentary R10.3.5, ACI 318 (2011) points out that the effect of this limitation is to restrict the reinforcement ratio in RC beams to about the same ratio as in editions of the Code before 2002. This last was $0.75 \rho_{b}$ and is equivalent to a net tensile strain limit of 0.00376 . The limit of 0.004 in the edition of the Code of 2011 is slightly more conservative. Since the previous values for $\varepsilon_{t}$ are similar, in this study a simplified maximum tensile reinforcement ratio $\rho_{\max }=$ $0.75 \rho_{b}$ will be considered.

\subsection{Comparison with experimental results}

The maximum and minimum longitudinal tensile reinforcement ratios $\left(\rho_{\min }\right.$ and $\left.\rho_{\max }\right)$ defined from the different codes of practice are computed for the tested 
Table 7. Limits for the tensile reinforcement ratios

\begin{tabular}{|c|c|c|c|c|c|c|c|c|c|c|}
\hline & & & \multicolumn{2}{|c|}{ MC90 } & \multicolumn{2}{|c|}{ MC2010 } & \multicolumn{2}{|c|}{$\mathrm{EC} 2$} & \multicolumn{2}{|c|}{ ACI 318 (2011) } \\
\hline \multicolumn{3}{|c|}{$\rho_{\min }(\%)$} & \multicolumn{2}{|c|}{0.15} & \multicolumn{2}{|c|}{$0.26 \frac{f_{l c t m}}{f_{y k}}$} & \multicolumn{2}{|c|}{0.15} & \multicolumn{2}{|c|}{$0.25 \frac{\sqrt{f_{c}^{\prime}}}{f_{y}} \geq 1.4 / f y$} \\
\hline \multicolumn{3}{|c|}{$\rho_{\max }(\%)$} & \multicolumn{2}{|c|}{$4 h / d$} & \multicolumn{2}{|c|}{$4 h / d$} & \multicolumn{2}{|c|}{$4 h / d$} & \multicolumn{2}{|c|}{$0.75 \rho_{b}$} \\
\hline Beam & $\mu_{\delta}$ & $\begin{array}{l}\rho \\
\%\end{array}$ & $\underset{\%}{\rho_{\min }}$ & $\underset{\%}{\rho_{\max }}$ & $\underset{\%}{\rho_{\min }}$ & $\underset{\%}{\rho_{\max }}$ & $\underset{\%}{\rho_{\text {min }}}$ & $\underset{\%}{\rho_{\max }}$ & $\underset{\%}{\rho_{\min }}$ & $\underset{\%}{\rho_{\max }}$ \\
\hline $1(23.5-0.13)$ & - & 0.13 & 0.15 & 4.33 & 0.09 & 4.33 & 0.15 & 4.33 & 0.35 & 1.38 \\
\hline $1(22.8-0.24)$ & 10.4 & 0.24 & 0.15 & 4.35 & 0.10 & 4.35 & 0.15 & 4.35 & 0.35 & 1.17 \\
\hline $1(22.0-0.38)$ & 5.9 & 0.38 & 0.15 & 4.36 & 0.09 & 4.36 & 0.15 & 4.36 & 0.35 & 1.09 \\
\hline $1(22.4-0.55)$ & 3.5 & 0.55 & 0.15 & 4.38 & 0.09 & 4.38 & 0.15 & 4.38 & 0.35 & 1.20 \\
\hline $1(28.5-0.99)$ & 2.0 & 0.99 & 0.15 & 4.41 & 0.12 & 4.41 & 0.15 & 4.41 & 0.35 & 1.37 \\
\hline $2(45.1-0.13)$ & - & 0.13 & 0.15 & 4.33 & 0.18 & 4.33 & 0.18 & 4.33 & 0.35 & 2.31 \\
\hline $2(42.1-0.24)$ & 12.4 & 0.24 & 0.15 & 4.35 & 0.17 & 4.35 & 0.17 & 4.35 & 0.35 & 1.94 \\
\hline $2(47.1-0.38)$ & 7.2 & 0.38 & 0.15 & 4.36 & 0.19 & 4.36 & 0.19 & 4.36 & 0.35 & 2.00 \\
\hline $2(49.2-0.55)$ & 4.5 & 0.55 & 0.15 & 4.38 & 0.20 & 4.38 & 0.20 & 4.38 & 0.35 & 2.23 \\
\hline $2(43.9-0.99)$ & 3.0 & 0.99 & 0.15 & 4.41 & 0.18 & 4.41 & 0.18 & 4.41 & 0.35 & 1.86 \\
\hline $2(47.0-1.55)$ & 1.7 & 1.55 & 0.15 & 4.44 & 0.19 & 4.44 & 0.19 & 4.44 & 0.35 & 1.96 \\
\hline $2(43.0-2.03)$ & 1.4 & 2.03 & 0.15 & 4.55 & 0.17 & 4.55 & 0.17 & 4.55 & 0.35 & 1.84 \\
\hline $3(52.1-0.13)$ & - & 0.13 & 0.15 & 4.33 & 0.21 & 4.33 & 0.21 & 4.33 & 0.35 & 2.51 \\
\hline $3(51.2-0.38)$ & 6.7 & 0.38 & 0.15 & 4.36 & 0.20 & 4.36 & 0.20 & 4.36 & 0.35 & 2.10 \\
\hline $3(52.4-0.55)$ & 3.9 & 0.55 & 0.15 & 4.38 & 0.21 & 4.38 & 0.21 & 4.38 & 0.35 & 2.31 \\
\hline $3(55.3-0.99)$ & 2.9 & 0.99 & 0.15 & 4.41 & 0.22 & 4.41 & 0.22 & 4.41 & 0.35 & 2.13 \\
\hline $3(53.4-1.55)$ & 2.0 & 1.55 & 0.15 & 4.44 & 0.21 & 4.44 & 0.21 & 4.44 & 0.34 & 2.11 \\
\hline $3(60.4-2.03)$ & 1.2 & 2.03 & 0.15 & 4.55 & 0.24 & 4.55 & 0.24 & 4.55 & 0.37 & 2.22 \\
\hline $3(51.6-2.69)$ & 1.0 & 2.69 & 0.15 & 4.71 & 0.20 & 4.71 & 0.20 & 4.71 & 0.35 & 2.07 \\
\hline
\end{tabular}

Symbology:

$d, h=$ effective depth and height of the cross section;

$f_{c}^{\prime}=$ concrete strength in compression;

$f_{c k}=$ charact. compressive strength of LWAC: $f_{\text {lctk }}=f_{c k}-8 \mathrm{MPa}$;

$f_{l c}=$ mean value of compressive strength of LWAC;

$f_{l c t m}=$ mean tensile strength for LWAC (Section 5.1.5.1 from Fib 2010: $f_{l c t m}=h_{l} 0.3\left(f_{l c k}\right)^{2 / 3}$ for $f_{l c k} £ 50 \mathrm{MPa}$ and $h_{l}=0.4+0.6 d_{l}$ / 2200, where $d_{l}$ is the oven-dry density of the LWAC $\left.\left(\mathrm{kg} / \mathrm{m}^{3}\right)\right)$;

$f_{y} \quad=$ value of the steel yielding stress;

$f_{y k}=$ characteristic value of the steel yielding stress;

$\lambda=$ modification factor to account for LWAC (the concrete used in this study incorporates normal-weight fine aggregate and lightweight coarse aggregate, then $\lambda=0.85$, Section 8.6.1 from ACI 318 2011);

$\rho_{b} \quad=$ long. steel reinforcement ratio that leads to the Balanced strain conditions: $\rho_{b}=\left(0.85 \beta_{1} f_{l c} / f_{y}\right)^{\prime}\left[600 /\left(600+f_{y}\right)\right]$.

LWAC beams (Table 7). The aim is to check if the code limitations, when applied to the test beams, meet the main objective of ensuring an adequate ductility.

Since it was observed that the trends for the deflection and curvature ductility indexes were similar (Section 4), only deflection ductility index will be used in this section. Table 7 includes the first beams of each series (beams with the lowest longitudinal tensile reinforcement ratio). The incorporation of such beams is important because they suffered a premature failure due to insufficient reinforcement (rupture of the steel), so the codes should not allow such beams.
From Table 7, it can be shown that ACI318 is clearly more restrictive as far as the maximum and minimum amount of longitudinal tensile steel reinforcement is concerned. In fact, except the first beams of each series, all other test beams are allowed by European codes, but not all are allowed by ACI 318 (2011) requirements.

With one exception, all codes do not allow Beams 1(23.5-0.13), 2(45.1-0.13) and 3(52.1-0.13). The exception is Beam 1(23.5-0.13) that is allowed by MC2010. As previously referred, those beams have not sufficient tensile reinforcement. Then, it can be state that almost 
all the studied codes provides adequate minimum limits for the longitudinal tensile reinforcement ratio, when applied to the tested LWAC beams. In addition, $\mathrm{ACI} 318$ do not allow Beams 1(22.8-0.24) and 2(42.1-0.24). Such beams have low longitudinal tensile reinforcement ratios but they showed to have a typical flexural behavior (see Section 3). From this point of view, the minimum limits for the longitudinal tensile reinforcement ratio specified by ACI 318 (2011) seems to be somewhat excessive when applied to the tested beams.

With respect to the beams with high longitudinal tensile reinforcement ratio, they are all allowed by the European codes. ACI 318 (2011) do not allow Beams 2(43.0-2.03) and 3(51.6-2.69) which have the lowest deflection ductility index values within each series. Beam 3(51.6-2.69) suffered a brittle failure with no inelastic deformation after the yielding of the reinforcement (see Fig. 4(c)) and should not be allowed by the codes of practice. From this point of view, the maximum limit for the longitudinal tensile reinforcement ratio specified by ACI 318 (2011) seems to be adequate when applied to the tested LWAC beams.

Table 7 shows that, when compared to European codes, ACI 318 (2011) gives higher guaranty for ductility for the tested LWAC beams. Such observation may be due to the inclusion, into the equations, of the amount of reinforcement relative to concrete strength. In fact, this parameter governs the flexural behavior of the beams. In European codes, the maximum longitudinal tensile reinforcement ratio is only fixed by means of a constant percentage of the cross section area.

Figures 9(a) to 9(e) present graphically the deflection ductility index as a function of the longitudinal tensile steel reinforcement ratio, regardless of the concrete strength and also shows on background the range of normative limit values $\rho_{\min }$ and $\rho_{\max }$ for the different studied codes of practice. Conventional points corresponding to the first beams of each series were also marked $($ symbol $\times)$. Once their deflection ductility indexes were not computed, a conventional minimum value was assumed. The arrow drawn over the points mean that the value of the deflection ductility index is actually higher, despite these beams are not desirable.

Figures 9(c) and 9(d) are related with ACI 318 (2011). Since the maximum tensile reinforcement ratio is related to the concrete strength, the corresponding range of values will be too large if all the beams were included in the same graph. In order to allow a better interpretation of the results, Figure 9(c) presents a graph for the beams from Series 1, while Figure 9(d) includes beams from Series 2 and 3. For these last series, the corresponding concrete strengths are not very different.

Observing Figures 9(a) to 9(e), it is clear that ACI 318 (2011) requirements give more guaranties as far as the ductility is concerned because of the upper limit of the longitudinal tensile reinforcement ratio.

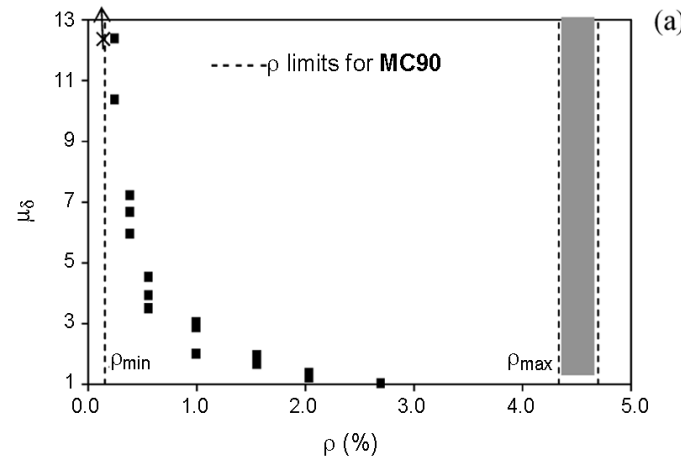

(a)
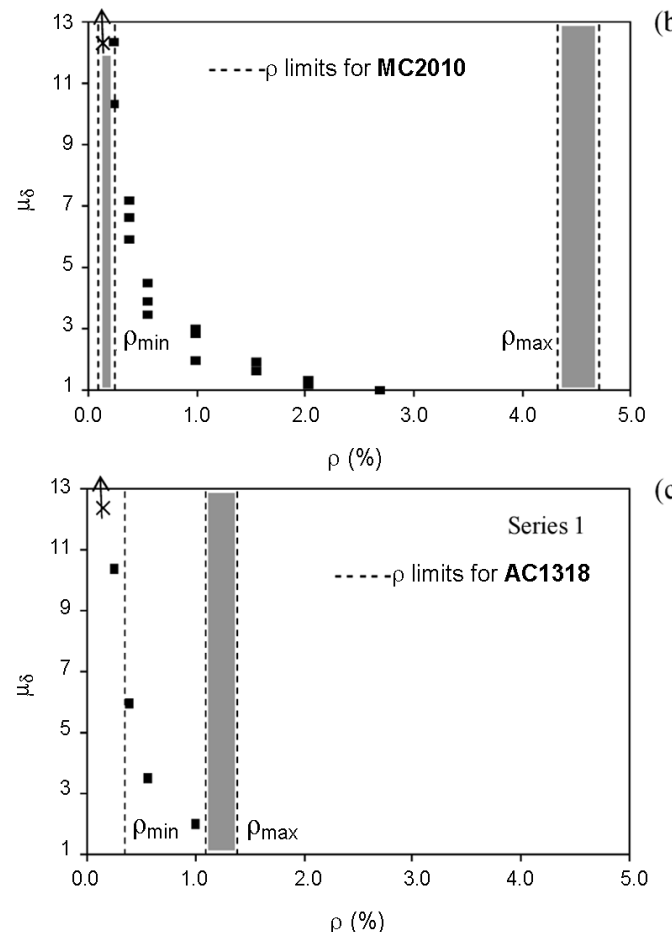

(c)
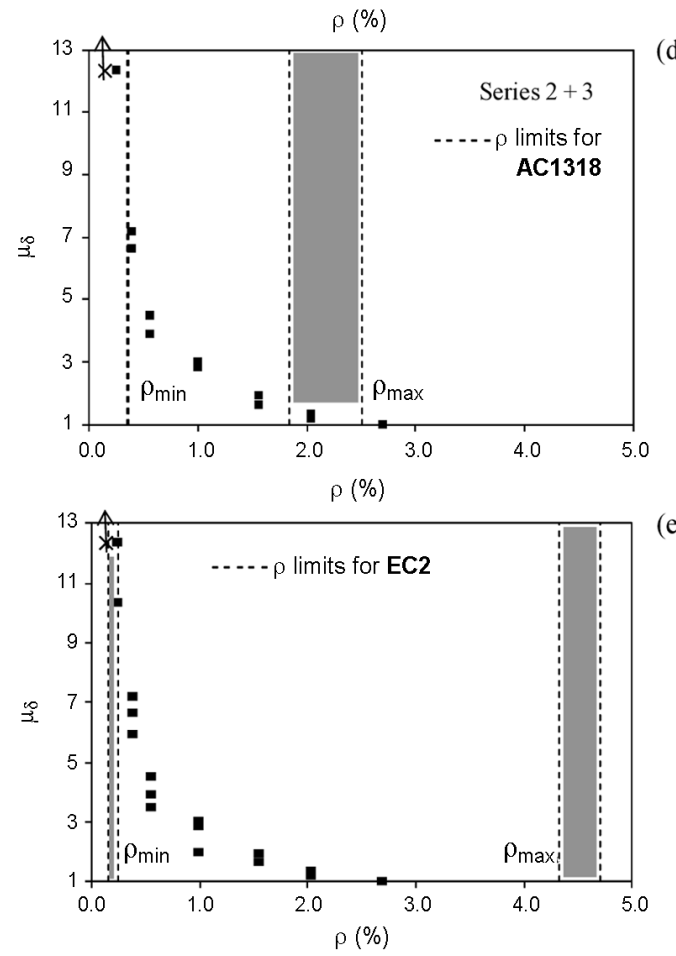

(e)

Fig. 9. Graphs $\rho-\delta_{i}$ : a) MC90; b) MC2010; c) and d) ACI 318 (2011); e) EC2 


\section{Conclusions}

In this study, a comparative analysis on the flexural ductility of LWAC beams was presented. The experimental results obtained using the flexural ductility indexes show good agreement with one another. It was observed that, for approximately constant values of concrete compressive strength, beams suffer a reduction in ductility with increasing longitudinal reinforcement ratio.

The results show that, for similar longitudinal tensile reinforcement ratios, an increase in the concrete compressive strength caused a slight increase in ductility.

It was also observed a high reduction on the flexural ductility as the longitudinal tensile reinforcement ratio increases until approximately $\rho \approx 1.5-2.0 \%$. After these values, ductility of the tested LWAC beams is very low and failure tends to be brittle, regardless of the compressive concrete strength. These limits are somewhat smaller when compared with the same ones previously reported by other authors for NWAC beams.

This seems to show that the range of longitudinal tensile reinforcement ratio compatible with flexural ductility are somewhat lower for LWAC beams, when compared to NWAC beams.

It is not possible to propose definitive limit values for the reinforcement ratio corresponding to the point from what this behavior takes place. Firstly, these limits are not clear, since such behavior was confirmed from a potential type tendency curve. Secondly, such limits, if they actually exist, they might be influenced by other parameters not investigated in this study, such as, the size effect, the slenderness, the concrete proportions, etc.

When comparing the limit values for the amount of longitudinal tensile steel reinforcement in different codes of practice, it was observed that ACI Code (ACI 318 (2011)) is more restricted than the European codes (MC90, MC2010 and EC2). The difference is more noticeable as far as the upper limit is concerned. It was observed that ACI Code ensures more flexural ductility for the tested LWAC beams than European codes.

\section{References}

ACI Committee 318. 2011. Building Code Requirements for Reinforced Concrete (ACI 318-11) and Commentary. American Concrete Institute.

ACI Committee 213. 2003. Guide for Structural LightweightAggregate Concrete (ACI 213R-03). American Concrete Institute.

Ahmad, S. H.; Barker, R. 1991. Flexural behavior of reinforced high-strength lightweight concrete beams, ACI Structural Journal 88(1): 69-77.

Ahmad, S. H.; Batts, J. 1991. Flexural behavior of reinforced high-strength lightweight concrete beams with web reinforcement, ACI Structural Journal 88(3): 251-58.

Ahmad, S. H.; Xie, Y.; Yu, T. 1995. Shear ductility of reinforced lightweight concrete beams of normal strength and high strength concrete, Cement \& Concrete Composites 17: 147159. http://dx.doi.org/10.1016/0958-9465(94)00029-X
Arslan, G.; Cihanli, E. 2010. Curvature ductility prediction of reinforced high-strength concrete beams sections, Journal of Civil Engineering and Management 16(4): 462-470. http://dx.doi.org/10.3846/jcem.2010.52

Balendran, R. V.; Zhou, F. P.; Nadeem, A.; Leung, A. Y. T. 2002. Influence of steel fibres on strength and ductility of normal and lightweight high strength concrete, Building and Environment 37(12): 1361-1367. http://dx.doi.org/10.1016/S0360-1323(01)00109-3

Bernardo, L. F. A.; Lopes, S. M. R. 2003. Flexural ductility of high-strength concrete beams, Structural Concrete 4(3): 135-154. http://dx.doi.org/10.1680/stco.2003.4.3.135

Bernardo, L. F. A.; Lopes, S. M. R. 2004. Neutral axis depth versus flexural ductility in high-strength concrete beams, Journal of Structural Engineering 130(3): 452-459.

http://dx.doi.org/10.1061/(ASCE)0733-9445(2004)130:3(452)

Bernardo, L. F. A.; Lopes, S. M. R., 2009 Plastic analysis of HSC beams in flexure, Materials and Structures 42(1): 51-69. http://dx.doi.org/10.1617/s11527-008-9366-x

Bogas, J. A.; Gomes, A. 2013. Compressive behaviour and failure modes of structural lightweight aggregate concrete - characterization and strength prediction, Materials and Design 46: 832-841. http://dx.doi.org/10.1016/j.matdes.2012.11.004

CEB. 1990. Ceb-fip model code 1990. Design Code Comité Euro-International du Béton. 437 p.

Cui, H. Z.; Lo, T. Y.; Memon, S. A; Xu, W. 2012. Effect of lightweight aggregate on the mechanical properties and brittleness of lightweight aggregate concrete, Construction and Building Materials 35: 149-158.

http://dx.doi.org/10.1016/j.conbuildmat.2012.02.053

Domagala, L. 2011. modification of properties of structural lightweight concrete with steel fibres, Journal of Civil Engineering and Management 17(1): 36-44. http://dx.doi.org/10.3846/13923730.2011.553923

Faust, T. 2000. Supplements to MC-90 for lightweight aggregate concrete, LACER 5(2000): 75-84.

Fib. 2000. Lightweight Aggregate Concrete, Recommended Extension to the Model Code 90. Fib Bulletin no 8. $119 \mathrm{p}$.

Fib. 2010. Model Code 2010 - Final draft, Volume 1. Fib Bulletin no $55.350 \mathrm{p}$.

Ho, J. C.-M.; Zhou, K. J.-H. 2011. Limited deformability design of high-strength concrete beams in low to moderate seismicity regions, Journal of Civil Engineering and Management 17(3): 409-423. http://dx.doi.org/10.3846/13923730.2011.594219

Jung, I. H.; Yang, W. J.; Yi, W. H.; Jee, S. W.; Lee, S. Y. 2007. Flexural behavior of high-strength lightweight concrete beam with eco lightweight aggregates, in $6^{\text {th }}$ International Conference on Fracture and Damage Mechanics, 17-19 July 2007, Madeira, Portugal, 733-736.

Liu, M. Y.; Lin, C.; Li, O.; Ding, Q. J.; Hu, S. G. 2006. Flexural performance of reinforced high-strength lightweight concrete beams, in $9^{\text {th }}$ International Symp. on Structural Engineering for Young Experts, 18-21 August 2006, Fuzhou, China, 264-270.

NP EN 1992-1-1. 2010. Eurocode 2: design of concrete structures - part 1: general rules and rules for buildings. Instituto Portugues da Qualitada, Portugal.

NP EN 206-1. 2007. Concrete: Part 1: Specification, performance, production and conformity. Instituto Portugues da Qualitada, Portugal.

Shehata, I. A. E. M.; Shehata, L. C. D. 1996. Ductility of highstrength concrete beams in flexure, in $4^{\text {th }}$ International Symposium on Utilization of High-Strength / High-Performance Concrete, May 1996, Paris, France, 945-953. 
Shin, S.-W.; Ghosh, S. K.; Moreno, J. 1989. Flexural ductility of ultra-high-strength concrete members, ACI Journal 86(4): 394-400.
Sin, L. H.; Huan, W. T.; Islam, M. R.; Mansur, M. A. 2010. Reinforced lightweight concrete beams in flexure, $A C I$ Structural Journal 108(1): 3-12.

Luís F. A. BERNARDO. Assistant Professor at the Department of Civil Engineering and Architecture of the University of Beira Interior, Portugal. He is a member of the research Centre C-made: Centre of Materials and Building Technologies, Portugal. His research interests include the mechanical behavior of structural concrete and the development of new structural materials and building systems.

Miguel C. S. NEPOMUCENO. Assistant Professor at the Department of Civil Engineering and Architecture of the University of Beira Interior, Portugal. He is a member of the research Centre C-made: Centre of Materials and Building Technologies, Portugal. His research interests include the construction materials, particularly the cement based materials. His professional interest includes also building physics, indoor environment and building systems.

Hugo A. S. PINTO. Master in Civil Engineering, PhD Student at the Department of Civil Engineering and Architecture of the University of Beira Interior, Portugal. He is a member of the research Centre C-made: Centre of Materials and Building Technologies, Portugal. His research interests include the cement based materials and the mechanical behavior of reinforced concrete structural elements. 